\title{
Efektivitas Model Project Based Learning Berorientasi eXe Learning dan Motivasi terhadap Hasil Belajar pada Materi Laju Reaksi
}

\author{
Agus Muliaman \\ Pendidikan Kimia, Universitas Malikussaleh, Indonesia \\ agusmuliaman@unimal.ac.id
}

\begin{abstract}
Abstrak
Penelitian ini bertujuan untuk mengetahui apakah terdapat perbedaan hasil belajar melalui Project Based Learning (PjBL) berorientasi eXe-Learning dan Direct Instruction berorientasi Macromedia Flash pada tingkat motivasi tinggi dan rendah pada materi laju reaksi di Universitas. Penelitian ini adalah penelitian quasi eksperimen kuantitatif dengan desain Pretest-Posttest Control Group Design. Populasi merupakan seluruh mahasiswa Prodi Pendidikan Kimia yang mengikuti perkuliahan mata kuliah Kimia Dasar, berjumlah sekitar 204. Teknik sampling menggunakan Purposive Sampling sehingga didapat sampel berjumlah 60 mahasiswa, yaitu 2 kelas yang masing-masing kelas berjumlah 30 mahasiswa. Instrumen dalam penelitian ini berupa tes soal objektif yang berjumlah 25 butir soal dan angket motivasi yang sudah valid dan reliebel. Penelitian ini menggunakan Analis varian (ANAVA) dua Jalur dengan GLM Univariate pada data $N$-gain dengan bantuan SPSS. Hasil penelitian menunjukkan bahwa terdapat perbedaan peningkatan hasil belajar melalui model PjBL berorientasi eXe-Learning dan Direct Instruction berorientasi Macromedia Flash pada tingkat motivasi tinggi dan rendah. Pembelajaran di kelas eksperimen menggunakan model PjBL berorientasi eXeLearning memperoleh hasil yang lebih baik dengan rata-rata $\mathrm{N}$-gain sebesar 0,73 sedangkan rata-rata $N$-gain kelas kontrol sebesar 0,63 sehingga didapat model PjBL berorientasi eXe-Learning lebih efektif digunakan dalam pembelajaran Laju Reaksi.
\end{abstract}

Kata kunci: exe learning, hasil belajar, laju reaksi, project based learning.

Dikirim: 6 Juni 2021

Direvisi: 22 Juni 2021

Diterima: 24 Juni 2021

\section{Identitas Artikel:}

Muliaman, A. (2021). Efektivitas Model Project Based Learning Berorientasi eXe Learning dan Motivasi Terhadap Hasil Belajar Pada Materi Laju Reaksi. Jurnal Ilmu Pendidikan (JIP) STKIP Kusuma Negara, 13(1), 51-57.

\section{PENDAHULUAN}

Pendidikan memiliki peranan penting dalam kehidupan masyarakat. Pendidikan mempengaruhi kecerdasan dan tingkat peradaban bangsa. Oleh sebab ini, setiap warga dituntut untuk terlibat aktif secara totalitas dalam meningkatkan mutu pendidikan di Indonesia. Tentu hal ini tidaklah mudah, banyak tantangan dan permasalahan yang harus kita hadapi bersama (Trianto, 2009).

Saat ini mutu pendidikan di Indonesia masih rendah dalam taraf global. Salah satu hal yang menyebabkan mutu pendidikan rendah dapat dilihat dari hasil belajar yang rendah, hal ini dapat terjadi diakibatkan materi sains khususnya kimia terkadang abstrak dan kongkrit sehingga sulit untuk dipelajari (Mellyzar \& Muliaman, 2020; Ginting, Muliaman, Lukman \& Mellyzar, 2020). Sebab lain ialah masih lemahnya proses pembelajaran yang terkesan tidak maksimal dan 
dalam pelaksanaannya pembelajaran diarahkan kepada kemampuan menghafal saja (Suyanti, 2010). Kemampuan menghafal ini masih tergolong lower order thingking yang jelas memenuhi targetan pendidikan. Menurut Arikunto (2013), pendidik yang baik ialah pendidik yang dapat membantu peserta didik untuk meningkatkan pemahaman bukan hanya hafalan. Semua hal ini dapat memicu peserta didik untuk tidak termotivasi dalam belajar.

Salah satu mata kuliah wajib dalam Kurikulum Program Studi Pendidikan di Fakultas Matematika dan Ilmu Pengetahuan Alam adalah mata kuliah konsep dasar kimia yang berbobot masing 2 SKS. Mata Kuliah kimia umum dipelajari mahasiswa pada semester 1 dan 2. Mata kuliah kimia umum berisikan pengetahuan dasar kimia yang mengantarkan kebahasan kimia yang lebih kompleks dan mendalam.

Selain itu, Wasonowati, Redjeki \& Ariani (2014) menyatakan kimia merupakan produk pengetahuan alam yang berupa fakta, teori, prinsip, dan hukum dari proses kerja ilmiah. Jadi dalam pelaksanaan pembelajaran harus mencakup tiga aspek utama yaitu produk, proses, dan sikap ilmiah. Mahasiswa sering kali kesulitan memahami materi kimia karena bersifat abstrak. Kesulitan tersebut dapat menyebabkan rendahnya pemahaman mahasiswa mengenai berbagai konsep kimia.

Kimia adalah salah satu mata pelajaran ilmu alam mempelajari gejala-gejala alam, tetapi mengkhususkan diri di dalam mempelajari struktur, susunan, sifat dan perubahan materi, serta energi yang menyertai perubahan materi (Magdalena, Mulyani \& van Hayus, 2014). Ilmu kimia juga mengandung konsep yang bersifat kompleks. Salah satu materi yang bersifat kompleks adalah materi laju reaksi, merupakan gabungan dari pengetahuan abstrak yang berupa persamaan laju reaksi, orde reaksi yang memerlukan latihan hitungan, faktor-faktor yang mempengaruhri laju reaksi, dan teori tumbukan. Namun secara kongkrit contoh peristiwanya sangat sering dijumpai dalam kehidupan sehari-hari misalnya besi berkarat, kertas terbakar, bom meledak dan lain lain.

Dari uraian di atas tentu dibutuhkan solusi agar pembelajaran dapat terlaksana dengan maksimal, juga bagaimana pendidik dapat menumbuhkan motivasi belajar dalam diri peserta didik sehingga mereka tidak terkesan belajar dengan keterpaksaan. Salah satu hal yang dapat kita terapkan inilah dengan penggunaan model pembelajaran yang tepat dan relevan dengan materi yang akan diajarkan. Selain itu penggunaan media juga dapat dilakukan pendidik lebih mudah dalam menyampaikan materi.

Salah satu model yang masih digunakan hingga saat ini ialah model PjBL berorientasi eXe learning. PjBL merupakan model pembelajaran banyak dikembangkan di negara-negara maju seperti Amerika Serikat. PjBL bermakna sebagai pembelajaran berbasis proyek (Al-Idrus \& Rahmawati, 2021; Purba \& Fitri, 2021), juga menurut Sumarti, Cahyono \& Munafiah (2015) model pembelajaran berbasis proyek sangat erat kaitannya dengan pendekatan ilmiah, karena pendekatan ilmiah merupakan ujung tombak yang mengintegrasikan ilmu belajar keduanya berawal dari munculnya masalah. Model ini juga sangat cocok digunakan dalam pembelajaran yang merujuk pada penguatan pemahaman konsep dan aplikasi dalam kehidupan sehari-hari, juga mendorong peserta didik untuk termotivasi dalam belajar, terlebih lagi dalam pembelajaran materi sains seperti kimia (laju reaksi). Hal ini didukung oleh beberapa peneliti berdasarkan penelitian 
sebelumnya diantaranya, Muliaman \& Mellyzar (2020), Pradita, Mulyani \& Redjeki (2015); Lukman, Martin \& Utama (2015), Yanti, Karyanto \& Sugiharto (2013) di mana hasil dalam penelitian mereka menunjukkan bahwa penggunaan PjBL meningkatkan hasil belajar dan keterampilan proses sains.

Dalam pembelajaran, agar kegiatan ini dapat berjalan maksimal, dosen harus mengusahakan agar mahasiswa yang diajar termotivasi dalam proses pembelajaran, jadi tidak terkesan terpaksa. Menurut Sardiman (2012), kata "motif" diartikan sebagai upaya yang mendorong seseorang untuk melakukan sesuatu. Motif dapat dikatakan sebagai daya penggerak dari dalam dan didalam subjek untuk melakukan aktivitas-aktivitas tertentu demi mencapai suatu tujuan. Motivasi ini mempunyai fungsi untuk mendorong mahasiswa berbuat, menentukan arah perbuatan, dan menyeleksi perbuatan. Motivasi ini juga dapat dipengengaruhi oleh teknik mengajar dan lingkungan sehingga dosen harus mencari model yang tepat dalam pembelajaran salah satunya PjBL.

Selain memilihi model pembelajaran yang tepat, hal yang yang dapat memaksimalkan pembelajaran ialah media pembelajaran. Media pembelajaran akan memudahkan dosen dalam menyampaikan materi yang akan diajarkan kepada mahasiswa. Salah maedia pembelajaran yang dapat digunakan ialah $e X e$ learning. eXe learning merupakan salah satu program aplikasi open-source yang dipergunakan untuk pembuatan bahan ajar berbasis e-learning. Bahan ajar yang disusun dengan $e X e$, tersusun secara hierarki yang benar mencakup topic, section dan unit. Susunan yang demikian akan memudahkan mahasiswa untuk lebih memahami materi pelajaran. eXe learning adalah media yang memudahkan pengajar dan akademisi dalam mendisain, mengembangkan dan publishing konten pembelajaran berbasiskan web tanpa diperlukan keahlian dalam penulisan HTML, XML, atau program aplikasi pembuatan web (Nurdin \& Setiawan, 2016). Dalam eXe juga dapat dibuat soal dengan tipe pilihan ganda, jawaban singkat, benar salah dan kuis sehingga dapat dipergunakan untuk uji kompetensi mahasiswa (Warjana \& Razaq, 2008).

Berdasarkan uraian di atas, peneliti membuat penelitian ini untuk mengetahui apakah terdapat perbedaan hasil belajar melalui PjBL berorientasi eXe-Learning dan Direct Instruction berorientasi Macromedia Flash pada tingkat motivasi tinggi dan rendah pada materi laju reaksi. Peneliti berharap hasil penelitian ini akan memberikan konstribusi besar terhadap permasalahan pendidikan sehingga mutu pendidikan Indonesia akan membaik.

\section{METODE PENELITIAN \\ Populasi dan Sampel}

Penelitian ini dilaksanakan di Universitas Negeri Medan, Prodi Pendidikan Kimia. Populasi ialah keseluruhan target yang menjadi objek penelitian yang akan diteliti baik secara kualitatif maupun kuantitatif (Sudjana, 2009). Populasi dalam Penelitian ini adalah seluruh peserta didik Pendidikan yang mengikuti perkuliahan mata kuliah kimia dasar sebanyak 204 peserta didik. Dari 204 peserta didik dilakukan purposive sampling sehingga didapat sampel sebanyak 60 peserta didik yang terdiri dari 1 kelas eksperimen dan 1 kelas kontrol. 


\section{Teknik Analisis Data}

Adapun instrumen dalam penelitian ini adalah soal tes multiple choice sebanyak 25 soal dan angket motivasi 12 pernyataan. Instrumen di uji dengan: (1) uji validitas, (2) uji reliabilitas, (3) uji tingkat kesukaran dan (4) uji daya pembeda. Data yang akan dianalisis diperoleh melalui pretest, postest dan angket. Teknik analisis data berupa: (1) analisis data deskriptif (2) uji normalitas, (3) uji homogenitas dan (4) uji hipotesis. Jenis penelitian merujuk pada quasi eksperimen dengan design Prestest-Posttest Control Group Design, seperti pada Tabel 1.

Tabel 1. Rancangan Penelitian

\begin{tabular}{lcc}
\hline & \multicolumn{2}{c}{ Model Pembelajaran } \\
\cline { 2 - 3 } Motivasi Belajar & Kelas Eksperimen PjBL & Kelas Kontrol Direct \\
& Berorientasi eXe Learning & Instruction berorientasi \\
& berbasis Kolaboratif & Macromedia Flash \\
& $\left(\mathrm{A}_{1}\right)$ & $\left(\mathrm{A}_{2}\right)$ \\
\hline Tinggi $\left(\mathrm{B}_{1}\right)$ & $\mathrm{A}_{1} \mathrm{~B}_{1}$ & $\mathrm{~A}_{2} \mathrm{~B}_{1}$ \\
Rendah $\left(\mathrm{B}_{2}\right)$ & $\mathrm{A}_{1} \mathrm{~B}_{2}$ & $\mathrm{~A}_{2} \mathrm{~B}_{2}$ \\
\hline
\end{tabular}

Keterangan:

$\mathrm{A}_{1} \mathrm{~B}_{1}$ : Skor gain ternormalisasi peserta didik yang dibelajarkan model PjBL berorientasi eXe Learning berbasis Kolaboratif yang memiliki tingkat motivasi belajar tinggi

$\mathrm{A}_{1} \mathrm{~B}_{2}$ : Skor gain ternormalisasi peserta didik yang dibelajarkan model PjBL berorientasi eXe Learning berbasis Kolaboratif yang memiliki tingkat motivasi belajar rendah

$\mathrm{A}_{2} \mathrm{~B}_{1}$ : Skor gain ternormalisasi peserta didik yang dibelajarkan model Direct Instruction berorientasi Macromedia Flash yang memiliki tingkat motivasi belajar tinggi

$\mathrm{A}_{2} \mathrm{~B}_{2} \quad$ : Skor gain ternormalisasi peserta didik yang dibelajarkan model Direct Instruction berorientasi Macromedia Flash yang memiliki tingkat motivasi belajar rendah.

Adapun hipotesis pada penelitian ini ialah Ha: terdapat perbedaan peningkatan hasil belajar melalui PjBL berorientasi eXe-Learning dan Direct Instruction berorientasi Macromedia Flash pada tingkat motivasi tinggi dan rendah sedangkan $\mathrm{H}_{0}$ : Tidak terdapat perbedaan hasil belajar melalui PjBL berorientasi eXe-Learning dan Direct Instruction berorientasi Macromedia Flash pada tingkat motivasi tinggi dan rendah. Indikator keberhasilan dari penelitian ini ialah: (1) Hipotesis (Ha) diterima, (2) Hasil belajar kelas eksperimen lebih tinggi dari kelas kontrol.

\section{HASIL DAN PEMBAHASAN}

Adapun hipotesis pada penelitian ini ialah Ha: terdapat perbedaan peningkatan hasil belajar melalui PjBL berdasarkan penelitian yang telah dilakukan maka didapat data hasil belajar siswa dan motivasi yang dirangkum pada Tabel 2 . 
55 | Muliaman, Efektivitas Model Project Based Learning Berorientasi Exe Learning ...

Tabel 2. Data Rata-rata Hasil Belajar

\begin{tabular}{lccccc}
\hline \multicolumn{1}{c}{ Kelas } & $N$ & Pretes & Postes & $N$-gain & Motivasi \\
\hline Eksperimen & 30 & 39,9 & 85,9 & 0,73 & 72,2 \\
Kontrol & 30 & 38,0 & 76,3 & 0,63 & 64,5 \\
\hline
\end{tabular}

Pada Tabel 2 dapat dilihat nilai $\mathrm{N}$-gain kelas eksperimen sebesar 0,73 (tinggi) dan kelas kontrol sebesar 0,63 (Sedang), sedangkan untuk rata-rata motivasi diperoleh pada kelas eksperimen sebesar 72,2 (Tinggi) dan kelas kontrol sebesar 64,5. Secara deskriptif dalam dilihat bahwa kelas eksperimen lebih baik Kelas kontrol, itu artinya model PjBL berorinetasi eXe Learning memberikan dampak positif yang besar sehingga terlaksana pembelajaran yang lebih efektif.

Data di atas diuji dengan uji normalitas melalui Kolmogorov-Smirnov dengan bantuan SPSS. Pengujian normalitas dilakukan untuk mengetahui apakah data terdistribusi normal. Hasil Uji yang diperoleh kelas eksperimen dan kontrol ditampilkan pada Tabel 3. Pada Tabel 3 dapat dilihat bahwa semua data normal dikarenakan nilai sig > 0,05 sehingga data dapat digunakan pada uji selanjutnya.

Tabel 3. Data Hasil Uji Normalitas

\begin{tabular}{lcccc}
\hline \multicolumn{1}{c}{ Kelas } & $N$ & Pretes & Postes & $N$-gain \\
\hline Eksperimen & 30 & 0,200 & 0,110 & 0,102 \\
Kontrol & 30 & 0,200 & 0,200 & 0,116 \\
\hline Keterangan & & Normal & Normal & Normal \\
\hline
\end{tabular}

Data yang normal diuji dengan uji homogenitas melalui Levene's Test menggunakan SPSS, hal ini dilakukan agar dapat diketahui apakah data 2 kelompok sampel homegen atau tidak. Hasil uji dapat dilihat pada Tabel 4 yang menunjukkan bahwa data homogen dikarenakan nilai Sig. lebih dari 0,05.

Tabel 4. Data Hasil Uji Homogenitas

\begin{tabular}{lccc}
\hline \multicolumn{1}{c}{ Data } & Sig. & $\alpha$ & Keterangan \\
\hline Pretes & 0,468 & 0,05 & Data homogen \\
Postes & 0,843 & 0,05 & Data homogen \\
$N$-Gain & 0,204 & 0,05 & Data homogen \\
\hline
\end{tabular}

Data yang telah memenuhi prasyarat yaitu normal dan homegen maka diuji dengan uji hipotesis, hal ini dilakukan untuk menjawab apakah $\mathrm{Ha}$ atau $\mathrm{H}_{0}$ yang diterima. Uji hipotesis ini menggunakan Analis varian (ANAVA) dua Jalur dengan GLM Univariate pada data $N$-gain dengan bantuan SPSS.

Tabel 5. Data Hasil Uji Hipotesis

\begin{tabular}{|c|c|c|c|c|}
\hline Sumber & $\begin{array}{l}\text { Jumlah } \\
\text { Kuadrat }\end{array}$ & $\begin{array}{c}\text { Rata-Rata } \\
\text { Kuadrat }\end{array}$ & $F$ & Sig \\
\hline Konstanta & 24,683 & 24,683 & 4575,821 & 0,000 \\
\hline Model Pembelajaran & 0,53 & 0,53 & 9,805 & 0,003 \\
\hline Motivasi Belajar & 0,591 & 0,591 & 109,618 & 0,000 \\
\hline Model Pembelajaran*Motivasi Belajar & 0,206 & 0,206 & 38,135 & 0,000 \\
\hline
\end{tabular}


Hasil yang diperoleh ada pada Tabel 5, dimana didapati Ha diterima dikarenakan nilai Sig. $=0,003<0,05=\alpha$ yaitu terdapat perbedaan peningkatan hasil belajar melalui PjBL berorientasi eXe-Learning dan Direct Instruction berorientasi Macromedia Flash pada tingkat motivasi tinggi dan rendah.

Penyebab terjadinya perbedaan hasil belajar yang signifikan antara kelas eksperimen dan kelas kontrol ialah pada pembelajaran menggunakan model PjBL berorientasi eXe Learning, didapati peserta didik lebih terlibat aktif juga membuka kesempatan peserta didik untuk berimprovisasi dan lebih kreatif mulai dari menemukan masalah mendasar, mendesain proyek, menyusun jadwal, memonitoring, menguji hasil, sampai mengevaluasi sehingga peserta didik lebih termotivasi. Selain itu pendidik dapat terus memberikan masukan selama proses pembelajaran Hal ini juga didukung oleh Wekesa \& Ongunya (2016), pembelajaran ini memiliki kelebihan dalam hal membantu memilah, mengembangkan dan menumbuhkan motivasi dalam kelompok sehingga diperoleh hasil belajar yang tinggi.

\section{SIMPULAN}

Adapun kesimpulan yang diperoleh dalam penelitian ini, terdapat perbedaan hasil belajar melalui model PjBL berorientasi eXe-Learning dan Direct Instruction berorientasi Macromedia Flash pada tingkat motivasi tinggi dan rendah. Pembelajaran di kelas eksperimen menggunakan model PjBL berorientasi $e X e-$ Learning memperoleh hasil yang lebih baik dengan nilai sebesar 0,73 sedangkan nilai kelas kontrol sebesar 0,63 sehingga didapat model PjBL berorientasi $e X e$ Learning lebih efektif digunakan dalam pembelajaran Laju Reaksi.

\section{UCAPAN TERIMA KASIH}

Dalam kesempatan ini terucap terima kasih yang tak terhingga kepada sesama kepada seluruh pihak yang tidak dapat sebut satu-satu, membantu memberikan baik semngat, ide, tenaga, mapun tempat sehingga penelitian ini dapat terlaksana dengan baik.

\section{REFERENSI}

Al-Idrus, S. W., \& Rahmawati, R. (2021). Pengembangan Kemampuan Berpikir Kreatif Mahasiswa melalui Pembelajaran Berbasis Proyek pada Mata Kuliah Kimia Lingkungan di Masa Pandemic COVID 19. As-Sabiqun, 3(1), 14-25. https://doi.org/10.36088/assabiqun.v3i1.1117

Arikunto, S. (2013). Prosedur Penelitian. Jakarta: Rineka Cipta.

Ginting, F. W., Muliaman, A., Lukman, I. R., \& Mellyzar, M. (2020). Analysis of the Readiness of Education Study Program Students to Become Pre-Service Teacher Based on Teacher Competency Standards. Jurnal Pendidikan Fisika, 9(2), 120-127. https://doi.org/10.22611/jpf.v9i2.20941

Lukman, L. A., Martin, K. S., \& Utama, B. (2015). Efektivitas Metode Pembelajaran Project Based Learning (PjBL) Disertai Media Mind Mapping terhadap Prestasi Belajar Siswa pada Materi Pokok Sistem Koloid di Kelas XI 
IPA SMA Al Islam 1 Surakarta Tahun Ajaran 2013/2014. Jurnal Pendidkan Kimia, 4(1), 113-119.

Magdalena, O., Mulyani, S., \& Van Hayus, E. S. (2014). Pengaruh Pembelajaran Model Problem Based Learning dan Inquiry terhadap Prestasi Belajar Siswa Ditinjau dari Kreativitas Verbal pada Materi Hukum Dasar Kimia Kelas X SMAN 1 Boyolali Tahun Pelajaran 2013/2014. Jurnal Pendidkan Kimia, 3(4), $162-169$.

Mellyzar, M., \& Muliaman, A. (2020). Analisis Kesalahan Mahasiswa dalam Menyelesaikan Soal Ikatan Kimia. Lantanida Journal, 8(1), 40-52. http://dx.doi.org/10.22373/lj.v8i1.6420

Muliaman, A., \& Mellyzar, M. (2020). Peningkatan Hasil Belajar Menggunakan Model Project Based Learning pada Materi Laju Reaksi. Chemistry in Education, 9(2), 91-95.

Nurdin, S., \& Setiawan, W. (2016). Improving Students' Cognitive Abilities and Creative Thinking Skills on Temperature and Heat Concepts through an Exelearning-Assisted Problem Based Learning. International Journal of Scientific and Technology Research, 5(12), 59-63.

Pradita, Y., Mulyani, B., \& Redjeki, T. (2015). Penerapan Model Pembelajaran Project Based Learning untuk Meningkatkan Prestasi Belajar dan Kreativitas Siswa pada Materi Pokok Sistem Koloid Kelas XI IPA Semester Genap Madrasah Aliyah Negeri Klaten Tahun Pelajaran 2013/2014. Jurnal Pendidikan Kimia, 4(1), 89-96.

Purba, J., \& Fitri, R. A. (2021). Pengembangan Bahan Ajar Kimia Berbasis Proyek dengan Multimedia pada Materi Alkena di Sekolah Menengah Atas. Jurnal Inovasi Pembelajaran Kimia (Journal of Innovation in Chemistry Education), 3(1), 56-65. https://doi.org/10.24114/jipk.v3i1.23536

Sardiman, S. (2012). Interkasi dan Motivasi Belajar Mengajar. Depok: Rajawali Pers.

Sumarti, S. S., Cahyono, E., \& Munafiah, A. (2015). Project Based Learning Tools Development on Salt Hydrolysis Materials through Scientific Approach. IOSR Journal of Research \& Method in Education, 5(2), 1-5.

Suyanti, R. D. (2010). Srategi Pembelajaran Kimia. Yogyakarta: Graha Ilmu.

Trianto. (2009). Mendesain Model Pembelajaran Inovatif-Progresif. Jakarta: Kencana Prenada Media Group.

Warjana, W., \& Razaq, A. (2008). Membuat Bahan Ajar Berbasis Web dengan eXe. Jakarta: PT Alex Media Komputindo.

Wasonowati, R. R. T., Redjeki, T., \& Ariani, S. R. D. (2014). Penerapan Model Problem Based Learning (PBL) pada Pembelajaran Hukum-Hukum Dasar Kimia Ditinjau dari Aktivitas dan Hasil Belajar Siswa Kelas X IPA SMA Negeri 2 Surakarta Tahun Pelajaran 2013/2014. Jurnal Pendidikan Kimia (JPK, 3(3), 66-75.

Wekesa, N. W., \& Ongunya, R. O. (2016). Project Based Learning on Students' Performance in the Concept of Classification of Organisms Among Secondary Schools in Kenya. Journal of Education and Practice, 7(16), 25-31.

Yanti, D. E., Karyanto, P., \& Sugiharto, B. (2013). Pengaruh Model Project Based Learning (PjBL) terhadap Kemampuan Berpikir Kritis Siswa Kelas X SMA Negeri 2 Karanganyar Tahun Pelajaran 2012/2013. Bio-Pedagogi, 2(2), 9299. 